\title{
Pigmentos maculares
}

\author{
Macular pigments
}

\author{
RenataCanovas $^{1}$ \\ Marcela Cype $^{2}$ \\ Michel Eid Farah ${ }^{3}$ \\ Rubens Belfort Jr. ${ }^{4}$
}

\section{RESUMO}

A luteína e a zeaxantina são pigmentos amarelos que se localizam na mácula. Devido à sua localização, diminuem e filtram a quantidade de luz principalmente azul que chega aos fotorreceptores, atuam como antioxidantes e podem melhorar a qualidade visual. Esta é uma revisão do seu mecanismo de incorporação, ação, possíveis aplicações e conhecimento científico a respeito.

Descritores: Pigmentos da retina/fisiologia; Mácula lútea/fisiologia; Carotenóides; Luteína; Xantofilas; Vitaminas; Dietas alimentares; Idoso

\section{INTRODUÇ̃̃OO}

A luteína e a zeaxantina são pigmentos amarelos que se localizam na região macular, por isso também chamados de pigmentos maculares. Não são sintetizadas por nosso organismo, portanto necessitam ser obtidas por meio da ingesta diária de alimentos onde se encontram presentes. São encontradas nos vegetais e podem ser identificadas quantitativamente através da cromatografia líquida de alta performance (CLAP) quadro $1^{(1-3)}$.

A luteína é uma molécula lipossolúvel e após sua liberação no lúmen do trato gastrintestinal, é incorporada a lipoproteínas linfáticas formando micelas. A partir daí acredita-se que seja absorvida em sua maior parte na mucosa do intestino delgado e transportada até o fígado, onde lipoproteínas de baixa densidade e muito baixa (LDL e VLDL) facilitariam sua distribuição aos tecidos periféricos.

A quantidade de luteína presente nos diversos tecidos é bastante variável e acredita-se que existam substâncias que facilitem seu acúmulo em determinados locais. Em 2001 foi isolada a XBP (xanthophyl-binding-protein) que supostamente facilitaria o acúmulo seletivo de algumas xantofilas em locais específicos (luteína, zeaxantína e $\beta$-ciptoxantina) ${ }^{(4-5)}$.

Os pigmentos maculares localizam-se nos $7 \mathrm{~mm}^{2}$ do centro da retina. Em adultos, a zeaxantina é dominante no centro da fóvea, concentração que se reduz à medida que nos distanciamos do centro foveal. Inversamente ocorre um aumento na concentração de luteína com o aumento da distância em relação à fóvea. Portanto, encontramos uma relação L:Z de aproximadamente 1:2,4 centralmente e de $2: 1$ perifericamente: a zeaxantina concentra-se preferencialmente na fóvea e a luteína na perifóvea. Uma análise comparativa da relação L:Z versus a relação bastonetes:cones demonstrou proporcionalidade significativa para se postular que talvez $\mathrm{Z}$ estivesse relacionada aos cones e L aos bastonetes e que os fotorreceptores tivessem receptores específicos para os dois carotenóides ${ }^{(6)}$.

As xantofilas localizam-se na camada de fibras de Henle em primatas ${ }^{(5)} \mathrm{e}$ parecem estar relacionadas ao metabolismo dos segmentos externos dos fotorreceptores. Aproximadamente $25 \%$ do total dos carotenóides retinia- 


\begin{tabular}{|c|c|c|c|}
\hline \multicolumn{4}{|c|}{$\begin{array}{l}\text { Quadro 1. Quantidade de carotenóides maculares em alimentos } \\
\text { em mol\% }\end{array}$} \\
\hline Vegetais/frutas & $\begin{array}{l}\text { Luteína e } \\
\text { zeaxantina }\end{array}$ & Luteína & Zeaxantina \\
\hline Gema de ovo & 89 & 54 & 35 \\
\hline Milho & 86 & 60 & 25 \\
\hline Kiwi & 54 & 54 & 0 \\
\hline Uva Itália & 53 & 43 & 10 \\
\hline Abobrinha & 52 & 47 & 5 \\
\hline Abóbora & 49 & 49 & 0 \\
\hline Espinafre & 47 & 47 & 0 \\
\hline Pimenta laranja & 45 & 8 & 37 \\
\hline Pepino & 42 & 38 & 4 \\
\hline Ervilha & 41 & 41 & 0 \\
\hline Pimenta verde & 39 & 36 & 3 \\
\hline Suco de laranja & 35 & 15 & 20 \\
\hline Uvas verdes & 31 & 25 & 7 \\
\hline Couve-flor & 29 & 27 & 2 \\
\hline Cebolinha & 29 & 27 & 3 \\
\hline Feijão-verde & 25 & 22 & 3 \\
\hline Laranja & 22 & 7 & 15 \\
\hline Brócolis & 22 & 22 & 0 \\
\hline Maçã & 20 & 19 & 1 \\
\hline Manga & 18 & 2 & 16 \\
\hline Alface verde & 15 & 15 & 0 \\
\hline Suco de tomate & 13 & 11 & 2 \\
\hline Pêssego & 13 & 5 & 8 \\
\hline Pimenta amarela & 12 & 12 & 0 \\
\hline Nectarina & 11 & 6 & 6 \\
\hline Pimenta vermelha & 7 & 7 & 0 \\
\hline Tomate & 6 & 6 & 0 \\
\hline Cenoura & 2 & 2 & 0 \\
\hline Melão & 1 & 1 & 0 \\
\hline Damasco seco & 1 & 1 & 0 \\
\hline
\end{tabular}

nos são encontrados nos segmentos externos dos fotorreceptores, que é o mais susceptível ao dano por stress oxidativo ${ }^{(2-3,7)}$.

A densidade óptica de pigmentos maculares (DOPM) é a medida quantitativa destes carotenóides. É bastante variável e parece ser dependente de muitos fatores sendo a quantidade presente na dieta um dos mais importantes. Em curto prazo, estudos em pacientes com dieta rica em luteína e zeaxantina ou com suplementação por três ou mais meses resultaram em aumento na densidade dos carotenóides retinianos na maioria dos pacientes. Entretanto, a resposta interindividual à suplementação foi bastante variável, sugerindo que outros fatores influenciem sua biodisponibilidade, capacidade de absorção e transporte aos tecidos em que se acumulam.

O cozimento e a presença de gordura na dieta normalmente aumentam a biodisponibilidade da luteína e zeaxantina.

A genética teria um papel fundamental ${ }^{(8)}$. Em alguns estudos a densidade de pigmentos maculares foi menor em indivíduos com olhos azuis, verdes e cinzas do que em íris escuras $^{(3)}$. O tabagismo também é associado à baixa densidade de pigmentos maculares em vários estudos, o que pode ser causado pelo efeito pró-oxidação que poderia aumentar o "tur- nover" dos carotenóides no plasma. Pequenos estudos observacionais relatam manutenção ou discreta diminuição dos níveis de carotenóides com o avançar da idade e com o aumento da porcentagem de gordura corporal. Olhos com degeneração macular relacionada à idade apresentam quase sempre baixa densidade óptica, não se sabendo contudo exatamente se a doença seria a causa ou consequência da condição ${ }^{(10-11)}$.

\section{Propriedades ópticas}

O espectro de absorção dos pigmentos maculares tem sido objeto de estudo por mais de 50 anos. Em geral, absorvem luz na região azul do espectro (pico $460 \mathrm{~nm}$ ). Ocorre também absorção significativa em comprimentos de onda além do limite inferior de visibilidade $(<380 \mathrm{~nm})$. Parecem não absorver além de $530 \mathrm{~nm}^{(2)}$.

Acredita-se que indivíduos com baixa densidade óptica de pigmentos maculares teriam um risco maior para a evolução de degeneração macular relacionada à idade (DMRI). Além das evidências de que os pigmentos diminuiriam a irradiação luminosa nos fotorreceptores e atuariam como antioxidantes, os fatores de risco para sua baixa densidade são os mesmos para DMRI, o que constitui evidência circunstancial para a hipóte$\mathrm{se}^{(6)}$. Assim, atualmente existe um extenso investimento no estudo e desenvolvimento de técnicas que quantifiquem os pigmentos na mácula in vivo. A tecnologia identificaria precocemente indivíduos "de risco" para o desenvolvimento de degeneração da mácula (indivíduos com baixa densidade óptica) e traria a possibilidade de monitoramento da suplementação via oral destes pacientes ${ }^{(3)}$.

Os pigmentos podem ser quantificados utilizando-se técnicas ex vivo e in vivo. As técnicas ex vivo constituem análise de espécimes provenientes de autópsia: cromatografia líquida de alta performance e microdensitometria ${ }^{(6)}$. As técnicas in vivo dividem-se em testes psicofísicos (subjetivos) e físicos (objetivos). "Flicker heterochromatic photometry" e "motion photometry" são testes psicofísicos ${ }^{(3,12)}$. "Raman-scattering"(3,13), "scanning laser ophthalmoscope", "color matching", reflectometria e autofluorescência são testes físicos ${ }^{(3,14-15)}$.

A cromatografia separa a fração lipossolúvel dos carotenóides à medida que atravessam uma coluna de material (geralmente sílica ou grânulos de vidro), fazendo com que carotenóides diferentes apareçam em tempos diferentes de acordo com a polaridade ${ }^{(6)}$.

$\mathrm{Na}$ microdensitometria o tecido é fixado em solução de preservação. Amostras sanguíneas de concentração de L e Z informam sobre o transporte do nutriente. A densidade óptica está relacionada à deposição a longo prazo dos carotenóides na retina ${ }^{(5,11,16)}$.

A validade das tecnologias de medida in vivo é baseada na comparação da curva de densidade óptica encontrada com a curva da cromatografia líquida de alta performance, considerada a técnica mais fidedigna para obtenção da concentração in vitro ${ }^{(3)}$.

Métodos fotográficos de quantificação dos pigmentos são baseados na aquisição de duas imagens do polo poste- 
rior com a mácula ao centro obtidas com comprimentos de onda diferentes. A primeira por meio de estimulação com curto comprimento de onda (luz azul, a qual é significativamente absorvida pelos pigmentos) e a segunda por comprimento de onda médio (luz verde, a qual não é absorvida). As duas imagens são então superpostas e a densidade obtida por substração digital. Os pigmentos maculares podem também ser estimados com espectroscopia de Raman, onde microvibrações das moléculas de $\mathrm{L}$ e $\mathrm{Z}$ são proporcionais à sua densidade óptica após excitação com fonte de argônio, que produz excitação dos carotenóides utilizando fonte de argônio ${ }^{(3,13)}$.

Outro método óptico e objetivo utiliza a autofluorescência da lipofuscina, localizada no nível das células do epitélio pigmentado da retina. Esta fluorescência é emitida na amplitude de 520-800 $\mathrm{nm}$ e pode ser excitada in vivo entre 400 e $570 \mathrm{~nm}$. O método é baseado na atenuação da luz de excitação da fluorescência foveal pela presença dos pigmentos.

O Heidelberg retinal angiograph ${ }^{\circledR}$ modificado determina o mapa de densidade óptica dos pigmentos maculares, comparando a autofluorescência foveal (onde a concentração de pigmentos é maior) e perifoveal em imagens do fundo obtidas

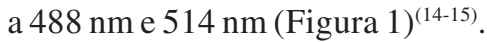

O "Heterochromatic flicker photometry" (HFP) é um método psicofísico, capaz de mensurar o espectro de sensibilidade e a densidade óptica dos pigmentos maculares. Utiliza fonte de diodo azul e verde para criar alvos de diferentes tamanhos apresentados contra um fundo azul para a fixação do olhar. $\mathrm{O}$ paciente usa controle manual com ajuste de frequência do flicker para suprimir a percepção da ação no alvo. Um computador analisa e traduz esta resposta, utilizando a frequência em que o indivíduo não tem mais a percepção do flicker para produzir um valor de densidade de filtração que corresponde a densidade óptica dos pigmentos maculares (Gráfico 1) ${ }^{(12)}$.

O método in vivo mais antigo e comumente utilizado é o "flicker", apesar de bastante subjetivo e demorado, o que torna sua realização cansativa e limitada em alguns pacientes, principalmente idosos.

\section{Possíveis funções dos pigmentos maculares}

\section{Aberração cromática}

Postula-se que os pigmentos atuem como um filtro óptico reduzindo o círculo de borramento e a dispersão luminosa, melhorando assim a sensibilidade ao contraste ${ }^{(2,17)}$.

\section{Visibilidade}

Wooten, et al. ${ }^{(18)}$ demostraram em modelo experimental que a presença de um filtro amarelo pode aumentar a visibilidade de um alvo por atuar reduzindo a quantidade de luz azul ao redor do alvo ${ }^{(2,18)}$. Os pigmentos são ausentes ou muito reduzidos em pacientes com albinismo e retinose pigmentária grave. A fotofobia destes pacientes poderia ser explicada em parte por sua inabilidade de diminuir o "glare" pela falta de pigmentos $^{(3,19-20)}$.

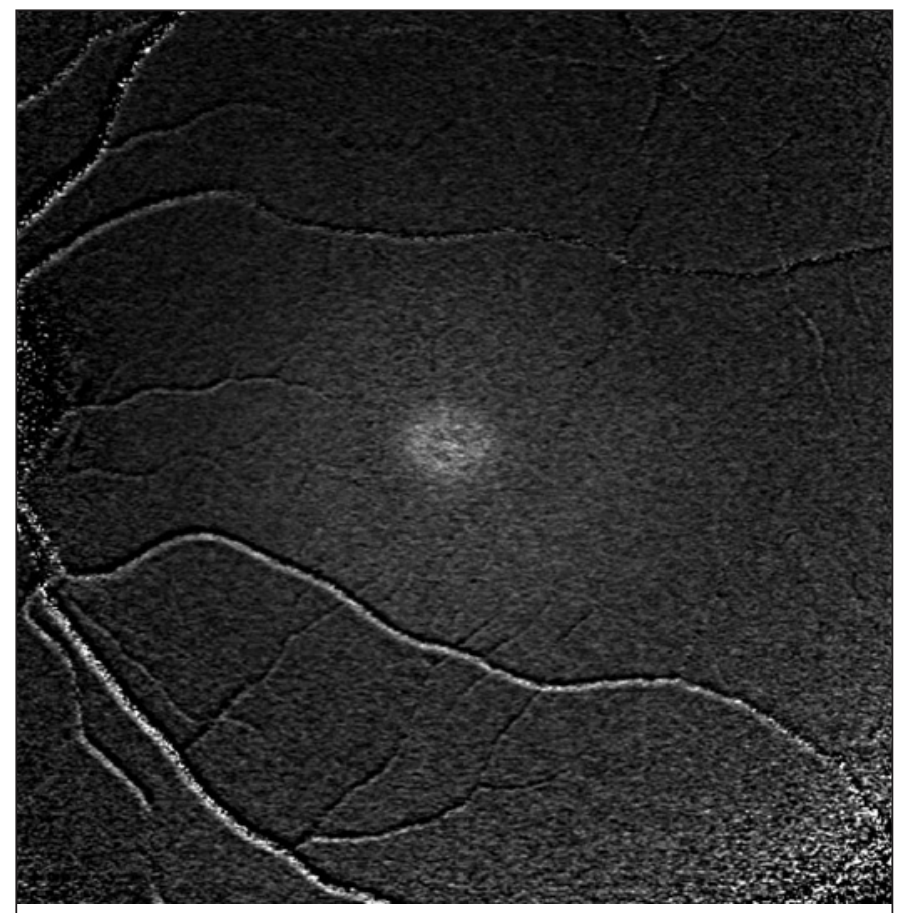

Fonte: Renata Canovas; New York Eye and Ear Infirmary - 2005

Figura 1 - Imagem resultante obtida com autofluorescência após subtração digital. Quanto mais clara a imagem, maior a concentração de pigmentos maculares em determinada região da mácula. Esta diferença nos tons de cinza é traduzida para uma escala numérica que representa a concentração dos pigmentos em cada ponto. Iniciando no centro da fóvea e colocando as medidas de concentração ponto a ponto distribuídas numa reta, obtemos a curva da densidade óptica.

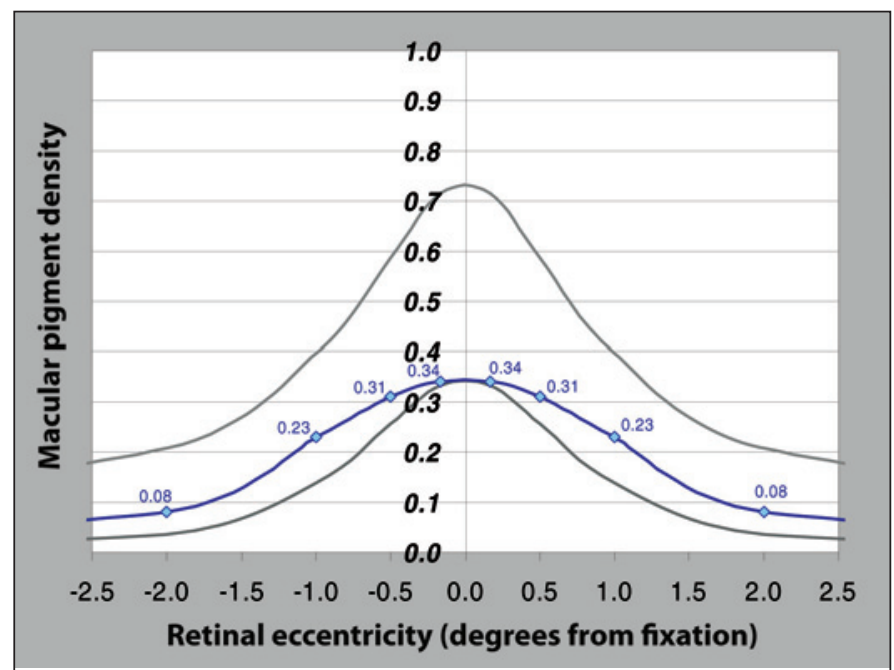

Fonte: Renata Canovas; New York Eye and Ear Infirmary - 2005

Gráfico 1 - Curva de densidade óptica dos pigmentos maculares medida com HFP

\section{Antioxidantes e DMRI}

A retina é o tecido metabolicamente mais ativo do corpo humano. A camada de fotorreceptores é mantida em altas ten- 
sões de oxigênio e contém grande concentração de ácidos graxos poli-insaturados, o que favoreceria o risco de dano tecidual proveniente principalmente de fontes luminosas (luz incidente e absorvida) que promovem reações químicas locais provocando liberação de espécies reativas de oxigênio (ânion superóxido, radicais livres hidroxilas e radicais hidroperóxidos) ${ }^{(3,21)}$.

Ham e colaboradores mediram os efeitos danosos da irradiação com luz de curto comprimento de onda na retina de macacos Rhesus. Dependendo da duração da exposição, a potência suficiente para resultar em dano era 70-1000 vezes menor em $441 \mathrm{~nm}$ do que para luz infravermelha de $1064 \mathrm{~nm}$ (duração de 1 a 1000 segundos). Assim, a mácula parece ser mais susceptível ao dano proveniente de luz de curto comprimento de onda ${ }^{(22)}$.

Os pigmentos maculares atuariam como um filtro protegendo a mácula por reduzir a quantidade de luz de comprimento de onda curto e neutralizariam espécies reativas de oxigênio liberadas tanto por dano luminoso como pelo próprio metabolismo retiniano interno.

Vários autores mostraram que os carotenóides têm propriedades antioxidantes específicas, reagindo com oxigênio singleto, radicais livres e também prevenindo peroxidação lipídica ${ }^{(22)}$.

A DMRI é uma doença com incidência crescente. Em suas formas avançadas, tanto seca (atrofia geográfica) como úmida (membrana neovascular sub-retiniana ou cicatriz disciforme), levam à perda de visão. $\mathrm{O}$ fator determinante para a evolução ou não de um paciente normal ou com as fases iniciais da doença para as formas graves seria a resposta do tecido ao estímulo inicial e resultante genético e ambiental (genótipo-fenótipo).

Consideramos fatores iniciadores ou promotores, a presença de determinados genes (CFH, BF, LOC387715, outros) somados à presença de estímulo proveniente de qualquer via pró-inflamatória (A2E, oxidação, doenças sistêmicas). Os fatores de risco modificáveis atuariam como moduladores do processo, favorecendo ou acelerando sua evolução (tabagismo, obesidade, altos níveis de colesterol, doenças sistêmicas) ou inibindo no caso de um estilo de vida "saudável" em geral. Os antioxidantes atuariam como um fator inibidor na tentativa de retardar ou impedir processo evolutivo da doença em indivíduos geneticamente predispostos ${ }^{(3,19)}$.

\section{Suplementação dietética}

Atualmente existem muitas fórmulas farmacêuticas contendo luteína e zeaxantina, geralmente associadas a vitaminas e outros antioxidantes. Podem conter diferentes formas de luteína. Os ésteres têm estrutura química diferente da luteína cristalina, que é a forma pura. Eles necessitariam de digestão enzimática no intestino delgado para sua absorção. Alguns autores sugerem a necessidade de uma dieta rica em ácidos graxos para que ocorra a mesma proporção de absorção da forma pura.

A suplementação aumenta os níveis séricos dos carotenóides assim como sua densidade óptica. Vários estudos estão em andamento na busca de números específicos para a concentração plasmática e densidade óptica em diferentes populações no intuito de identificar precocemente indivíduos "de risco" nos quais a suplementação seria apropriada.

O AREDS (Age-Related Eye Disease Study) avaliou os efeitos da suplementação com altas doses de vitaminas C, E, beta-caroteno e zinco na progressão de DMRI e na acuidade visual. Os resultados de cinco anos do estudo mostraram diminuição significativa na evolução para DMRI avançada no grupo que recebeu antioxidantes e zinco nos pacientes definidos como categorias 3 e 4 . A definição de DMRI avançada no estudo abrangia a presença de sinais de neovascularização e o desenvolvimento de atrofia geográfica central.

Os pacientes classificados na categoria 3 englobaram aqueles com ausência de DMRI avançada em ambos os olhos (ausência de neovascularização e atrofia geográfica central) e pelo menos um olho com acuidade visual de 20/32 ou melhor com pelo menos uma drusa grande (que mede $125 \mu$ ) ou extensa área de drusas intermediárias (que medem 63-124 $\mu$ ) cuja área total acometida pela presença das drusas seja $\geq 360 \mu$ se drusas moles ou $\geq 666 \mu$ se drusas duras ou atrofia geográfica que não envolva o centro da mácula ou ainda qualquer combinação destes achados.

$\mathrm{Na}$ categoria 4 os pacientes apresentam acuidade visual de 20/32 ou melhor em um olho sem a presença de DMRI avançada (se atrofia geográfica, que não envolva o centro da fóvea neste) e um olho com DMRI avançada ou acuidade visual pior que 20/32 atribuída à DMRI.

A análise final dos dados mostra uma redução no risco de progressão de $25 \%$ no grupo que recebeu antioxidantes + zinco quando comparados com o grupo placebo para estas duas categorias de pacientes.

A importância clínica da redução no desenvolvimento de DMRI avançada foi corroborada pelo efeito na acuidade visual destes pacientes, que quando comparados ao grupo placebo, tiveram uma redução estatisticamente significativa no risco de perda de 15 ou mais linhas. Esta redução foi de $27 \%$ no grupo que recebeu antioxidantes + zinco.

Desta forma, de acordo com os dados do AREDS, pessoas acima de 55 anos devem ter suas pupilas dilatadas para a determinação de seu risco de desenvolver DMRI avançada. Aqueles com drusas intermediárias, pelo menos uma drusa grande ou atrofia geográfica não-central em um ou ambos os olhos ou aqueles com DMRI avançada ou perda da visão em um olho por DMRI e que não apresentem contraindicações (como o tabagismo pois associado ao beta-caroteno aumenta o risco de câncer de pulmão), deveriam ser considerados candidatos ao uso de suplementação com antioxidantes + zinco $^{(23)}$.

Os resultados em longo prazo, para os pacientes que completaram o estudo até 10 anos reafirmaram o benefício, apresentando uma redução em $27 \%$ na probabilidade de progressão para DMRI avançada nos pacientes categorias 3 e 4 . Além disso, o estudo redefiniu as categorias de classificação para uma chamada "Escala simples", na qual os dois olhos do paciente contribuem com pontos de acordo com as alterações apresentadas (drusas grandes e alterações de pigmentação) 
para um "score" que estima o risco de progressão e de perda visual da doença( ${ }^{(24)}$.

Os efeitos da suplementação oral com 10 mg de luteína, $20 \mathrm{mg}$ de vitamina E $18 \mathrm{mg}$ de nicotinamida por 180 dias em DMRI foram analisados por Falsini et al. Eletrorretinograma focal mediu a resposta da retina central. Os resultados mostraram um aumento significativo na amplitude do eletrorretinograma nos pacientes suplementados quando comparados ao grupo que não a recebeu ${ }^{(25)}$.

Recentemente foram revisados dados demográficos, estilo de vida e características médicas de 4.519 participantes de 60 a 80 anos de idade do AREDS. Foram classificados em diferentes grupos de acordo com fotografias coloridas de fundo. A ingesta de nutrientes (carotenóides e vitaminas A, E e C) foi estimada por questionário de frequência de alimentação preenchidos pelos próprios pacientes. A presença de luteína/zeaxantina na dieta foi inversamente associada com neovascularização de coróide, atrofia geográfica e drusas grandes ou intermediárias em grande quantidade ${ }^{(26)}$.

O LAST (Lutein and Antioxidant Supplementation Study) foi um estudo prospectivo, randomizado, duplo-cego, placebocontrolado que acompanhou 90 pacientes com DMRI Atrófica. Os pacientes foram divididos em três grupos, que receberam $10 \mathrm{mg}$ de luteína, $10 \mathrm{mg}$ luteína com outros anioxidantes, vitaminas e minerais e placebo por 12 meses. No primeiro e segundo grupos os pacientes demonstraram melhora na acuidade visual para longe e perto, sensibilidade ao contraste, "glare", distorção na tela de Amsler e aumento de aproximadamente 50\% na densidade óptica de pigmentos maculares ${ }^{(27)}$.

O POLA (Pathologies Oculaires Liées a l'Age) foi um estudo prospectivo designado para identificar fatores de risco para catarata e DMRI. O estudo foi aberto à inclusão de residentes do sul da França com idade igual ou superior a 60 anos. Os pacientes foram submetidos a exame oftalmológico completo, entrevista pessoal com aplicação de questionário e colheita de amostra sanguínea em jejum para análises laboratoriais na mesma manhã do exame oftalmológico. Os olhos foram classificados em relação à catarata e DMRI, e os níveis séricos de carotenóides medidos separadamente por cromatografia líquida de alta performance. Os resultados sugerem fortemente a relação de proteção de altas concentrações plasmáticas de zeaxantina e luteína contra o desenvolvimento de DMRI e catarata nuclear ${ }^{(28)}$.

As evidências demonstram que os pigmentos maculares teriam um papel importante no diagnóstico precoce, acompanhamento e prevenção de doenças oculares relacionadas ao envelhecimento (Catarata e DMRI). A literatura relacionada é crescente e no AREDS II, grande estudo multicêntrico atual iniciado em 2006, além de antioxidantes (Vitaminas C, E) e zinco, os pacientes recebem $10 \mathrm{mg}$ de luteína, $2 \mathrm{mg}$ de zeaxantina (FloraGlo) e ômega-3. O objetivo deste estudo é avaliar os efeitos da suplementação dietética das xantofilas e ômega-3 no desenvolvimento de DMRI avançada, catarata e perda moderada da acuidade visual. Além disso, estudar os efeitos da eliminação do beta-caroteno e da diminuição da quantidade de zinco da formulação original do AREDS.

Pacientes de 50 a 85 anos com drusas grandes em ambos os olhos ou em um olho e DMRI avançada no outro olho (neovascularização ou atrofia geográfica central) foram elegíveis para o estudo se tivessem meios claros o suficiente para a realização das fotografias de fundo. A inclusão de pacientes terminou em junho de 2008 e a previsão de término do estudo é para dezembro de 2012.

\section{ABSTRACT}

Lutein and Zeaxanthin are yellow pigments located at the macula. Because of your location macular pigments decrease and filter the amount of blue light that reach photoreceptors, protect the outer retina from oxidative stress and may improve the vision quality. This is a review regarding incorporation mechanism, function and knowledge update.

Keywords: Retinal pigments/physiology; Macula lutea/physiology; Carotenoids; Lutein; Xanthophylls; Vitamins; Dietary supplements; Aging

\section{REFERÊNCIAS}

1. Snodderly DM, Auran JD, Delori FC. The macular pigment. II: Spatial distribution in primate retinas. Invest Ophthalmol Vis Sci. 1984;25(6):674-85.

2. Weiser H, Kormann AW. Provitamin A activities and physiological functions of carotenoids in animals. Relevance to human health. Ann N Y Acad Sci. 1993; 691:213-5.

3. Davies NP, Morland AB. Macular pigments: their characteristics and putative role. Prog Retin Eye Res. 2004;23(5):533-59.

4. Erdman JW Jr, Bierer TL, Gugger ET. Absorption and transport of carotenoids. Ann N Y Acad Sci. 1993;691:76-85. Review.

5. Zaripheh S, Erdman JW Jr. Factors that influence the bioavailablity of xanthophylls. J Nutr. 2002;132(3):531S-534S.

6. Bone RA, Landrum JT, Fernandez L, Tarsis SL. Analysis of the macular pigment by HPLC: retinal distribution and age study. Invest Ophthalmol Vis Sci. 1988;29(6):843-9.

7. Rapp LM, Maple SS, Choi JH. Lutein and zeaxanthin concentrations in rod outer segment membranes from perifoveal and peripheral human retina. Invest Ophthalmol Vis Sci. 2000;41(5):1200-9.

8. Broekmans WM, Berendschot TT, Klöpping-Ketelaars IA, de Vries AJ, Goldbohm RA, Tijburg LB, et al. Macular pigment density in relation to serum and adipose tissue concentrations of lutein and serum concentrations of zeaxanthin. Am J Clin Nutr. 2002;76(3):595-603.

9. Mares J. Carotenoids and eye disease: epidemiological evidence. In: Krinsky NI, Mayne ST, Sies H, eds. Carotenoids in Health and Disease. New York, NY: Marcel Dekker Inc; 2004.

10. Rock CL, Thornquist MD, Neuhouser ML, Kristal AR, Neumark-Sztainer D, Cooper DA, et al. Diet and lifestyle correlates of lutein in the blood and diet. J Nutr. 2002;132(3):525S-530S.

11. Curran-Celentano J, Hammond BR Jr, Ciulla TA, Cooper DA, Pratt LM, Danis RB. Relation between dietary intake, serum concentrations, and retinal concentrations of lutein and zeaxanthin in adults in a Midwest population. Am J Clin Nutr. 2001;74(6):796-802.

12. Snodderly DM, Mares JA, Wooten BR, Oxton L, Gruber M, Ficek T; CAREDS Macular Pigment Study Group. Macular pigment measurement by heterochromatic flicker photometry in older subjects: the carotenoids and agerelated eye disease study. Invest Ophthalmol Vis Sci. 2004;45(2):531-8.

13. Bernstein PS, Yoshida MD, Katz NB, McClane RW, Gellermann W. Raman detection of macular carotenoid pigments in intact human retina. Invest Ophthalmol Vis Sci. 1998;39(11):2003-11. 
14. Delori FC. Autofluorescence method to measure macular pigment optical densities fluorometry and autofluorescence imaging. Arch Biochem Biophys. 2004; 430(2):156-62

15. Trieschmann M, Spital G, Lommatzsch A, van Kuijk E, Fitzke F, Bird AC, Pauleikhoff D. Macular pigment: quantitative analysis on autofluorescence images. Graefes Arch Clin Exp Ophthalmol. 2003;241(12):1006-12.

16. Handelman GJ, Snodderly DM, Krinsky NI, Russett MD, Adler AJ. Biological control of primate macular pigment. Biochemical and densitometric studies. Invest Ophthalmol Vis Sci. 1991;32(2):257-67

17. Howarth PA, Bradley A. The longitudinal chromatic aberration of the human eye, and its correction. Vis Res. 1986;26(2):361-6.

18. Wooten BR, Hammond BR. Macular pigment: influences on visual acuity and visibility. Prog Retin Eye Res. 2002;21(2):225-40.

19. Whitehead AJ, Mares JA, Danis RP. Macular pigment: a review of current knowledge. Arch Ophthalmol. 2006;124(7):1038-45. Review.

20. Hammond BR Jr, Wooten BR, Curran-Celentano J. Carotenoids in the retina and lens: possible acute and chronic effects on human visual performance. Arch Biochem Biophys. 2001;385(1):41-6.

21. Wiegand RD, Joel CD, Rapp LM, Nielsen JC, Maude MB, Anderson RE Polyunsaturated fatty acids and vitamin $\mathrm{E}$ in rat rod outer segments during light damage. Invest Ophthalmol Vis Sci. 1986;27(5):727-33.

22. Moon ME, Clarke AM, Ruffolo JJ Jr, Mueller HA, Ham WT Jr. Visual performance in the rhesus monkey after exposure to blue light. Vision Res. 1978; 18(11):1573-7.

23. Age-Related Eye Disease Study Research Group. A randomized, placebo-controlled, clinical trial of high-dose supplementation with vitamins $\mathrm{C}$ and $\mathrm{E}$ and beta carotene for age-related cataract and vision loss: AREDS report $\mathrm{n}^{\circ}$ 9. Arch Ophthalmol 2001;119(10):1439-52. Erratum in: Arch Ophthalmol. 2008;126(9):1251.

24. SanGiovanni JP, Chew EY, Clemons TE, Davis MD, Ferris FL $3^{\text {rd }}$, Gensler GR, Kurinij N, Lindblad AS, Milton RC, Seddon JM, Sperduto RD; AgeRelated Eye Disease Study Research Group. The relationship of dietary lipid intake and age-related macular degeneration in a case-control study: AREDS Report № 20. Arch Ophthalmol. 2007;125(5):671-9.

25. Falsini B, Piccardi M, Iarossi G, Fadda A, Merendino E, Valentini P. Influence of short-term antioxidant supplementation on macular function in age-related maculopaty: a pilot study including electrophysiologic assessment. Ophthalmology. 2003;110(1):51-60; discussion 61.

26. Age-Related Eye Disease Study Research Group, SanGiovanni JP, Chew EY, Clemons TE, Ferris FL $3^{\text {rd }}$, Gensler G, Lindblad AS, Milton RC, Seddon JM, Sperduto RD. The relationship of dietary carotenoid and vitamin A, E, and C intake with age-related macular degeneration in a case-control study: AREDS Report No 22. Arch Ophthalmol. 2007;125(9):1225-32. Comment in: Arch Ophthalmol. 2008;126(9):1313; author reply 1313-4.

27. Richer S, Stiles W, Statkute L, Pulido J, Frankowski J, Rudy D, et al. Doublemasked, placebo-controlled, randomized trial of lutein and antioxidant supplementation in the intervention of atrophic age-related macular degeneration: the Veterans LAST study (Lutein Antioxidant Supplementation Trial). Optometry. 2004;75(4):216-30.

28. Delcourt C, Carrière I, Delage M, Barberger-Gateau P, Schalch W; POLA Study Group. Plasma lutein and zeaxanthin and other carotenoids as modifiable risk factors for age-related maculopathy and cataract: the POLA Study. Invest Ophthalmol Vis Sci. 2006;47(6):2329-35. 